\title{
Contribution to toxicity assessment of Dinophysis acuminata (Dinophyceae)
}

\author{
Claire Marcaillou ${ }^{1}$, Florence Mondeguer ${ }^{1}$ and Patrick Gentien ${ }^{2}$ \\ ${ }^{1}$ IFREMER-Nantes Rue de l'lle d'Yeu, BP 21105, 44311 Nantes, France \\ ${ }^{2}$ CREMA-l'Houmeau, Place du Séminaire, BP5, 17137 L'Houmeau, France \\ Corresponding author :Claire.Marcaillou@ifremer.fr
}

\begin{abstract}
Blooms of Dinophysis in French coastal waters are implicated in most bans on marketing commercial bivalves. However, the relation between Dinophysis cell density and shellfish toxicity is not always consistent. Discrepancies may be due to the simple fact that it is nearly impossible to compare an integral over a few days (shellfish toxin content) and water samples. Furthermore, it seems that cells may have a variable specific toxicity. This work focuses on the variability in cell toxicity taking into account recent findings and using liquid chromatography coupled to mass spectrometry with an ion trap and electrospray interface. Esterified analogues of okadaic acid (DTX-4 and diol-esters) have been identified in cultures of Prorocentrum lima, another okadaic acid producer. These analogues are inactive on some protein phosphatases, contrary to okadaic acid, and seem to protect the cell from harmful effects by the toxin and to be enzymatically hydrolyzed during cell lysis. In order to document specific toxicity and to validate the presence of these analogues, $D$. acuminata concentrates were subjected to two separate heating and freeze/thaw procedures, respectively inhibiting or promoting hydrolysis. This paper reports on the high variability of $D$. acuminata specific toxicity and the presence of esters found in half of the samples only.
\end{abstract}

Keywords: Dinophysis acuminata - dinophysistoxins - okadaic acid - liquid chromatographyelectrospray ionization mass spectrometry 


\section{Introduction}

Several species of Dinophysis produce toxins known as dinophysistoxins (DTXs,) potentially causing gastroenteritis-type food poisoning once accumulated by filter-feeding molluscs. In France, Dinophysis has been the major cause of economic losses suffered by shellfish farmers. The relation between Dinophysis spp and mussel toxicity outbreaks is relatively well established along the Atlantic and English Channel coastlines: e.g. in Bay of Seine in 1995 (Marcaillou-Le Baut et al., 2001). However, some cases of high shellfish toxicity with low or zero cell counts in the water, or vice versa have been observed in monitoring surveys. Jackson and Silke (1995) have reported on the difficulty of relating toxic cell count with shellfish toxicity, hense preventing the use of cell counts as a prediction tool for monitoring purposes. Variability in cell toxin content is one of the factors explaining this lack of relation. In Canada, Marr et al. (1992) found that phytoplankton samples in which Dinophysis spp predominate do not always contain detectable DTXs. Several publications have since then shown such variability. For $D$. acuminata, the reported toxicity ranges from non-detectable (Lee et al., 1989; Hoshiai et al., 1997) to around $50 \mathrm{pg}^{-1}$ cell $^{-1}$ okadaic acid (Andersen et al., 1996; Sato et al., 1996).

Concurrently with these investigations on Dinophysis, Hu et al. (1995a,b) have detected okadaic acid-related compounds in Prorocentrum lima, another benthic dinoflagellate known to produce DTXs. The terminal acid function of okadaic acid is esterified with chains of various length (diol-esters and DTX4), which renders them inactive on some protein phosphatases (PP2A and PP1, Bialojan \& Takaï, 1988). Okadaic acid being a powerful inhibitor of these proteins, the authors have hypothesized that these inactive esters may represent the primary synthesized form of DTXs. Quilliam et al. have actually shown in 1996 that a majority of DTXs in a $P$. lima culture are found in DTX4 form (okadaic acid -sulfated ester), and concluded that a more comprehensive analysis of toxins would be required for a more realistic assessment of phytoplankton toxicity.

This paper reports on the levels and variations of $D$. acuminata toxicity taking into account these recent findings.

\section{Material and methods}

\section{Sample collection and treatment}

The protocol described by Quilliam (1996) was adapted to natural samples in order to screen for the usual toxins and their esterified forms, if any, via indirect quantification, with and without promoting the enzymatic hydrolysis of esterified forms 
Seawater samples were collected during four sampling cruises during Dinophysis bloom outbreaks, at a single sampling station located $8 \mathrm{~km}$ off the Southern Brittany coast. Sampling depth was chosen according to particles populations measured by an in situ particle size analyzer (Gentien et al., 1995). Water samples (approximately $400 \mathrm{~L}$ ) were pumped with a peristaltic pump, then prefiltered over a $100-\mu \mathrm{m}$ screen, with final concentration over a $20-\mu \mathrm{m}$ sieve (final volume: approx. $300 \mathrm{~mL}$ ). The second sieve was kept permanently submerged to prevent cell damage. The concentrate was kept under constant low agitation to ensure homogeneity, and divided into three subsamples. One Lugol-fixed subsample was set aside for subsequent cell count. The second subsample (named heated fraction or A) was immersed for 10 min at $100{ }^{\circ} \mathrm{C}$ in a water-bath in order to block the enzymatic activity, then cooled down to ambient temperature and immersed in liquid nitrogen. The third subsample (named unheated fraction or B) was immediately immersed in liquid nitrogen. All samples were preserved at $-80{ }^{\circ} \mathrm{C}$ in the laboratory until analyzed.

\section{Dinophysis cell density}

Dinophysis cell density was estimated with a reverse microscope in a $10-\mathrm{mL}$ subsample of the lugol-fixed suspension (Utermöhl, 1958). Except for the occasional presence of a couple of $D$. rotundata cells, the cells observed were related to the acuminata group. When needed, the suspension was diluted so as not to exceed few hundred cells in the entire chamber. The standard error on three replicates of three independent samples was estimated to $15 \%$.

\section{Toxin analysis}

Prior to extraction, all samples were allowed to thaw for 24 hours at room temperature, before sonication and centrifugation for $20 \mathrm{~min}$ at $3000 \mathrm{rpm}$. The extraction protocol, inspired from Susuki et al (1997), was adapted for use with an automatic sample processor (ASPEC Xli, Gilson) to ensure optimum reproducibility (Mondeguer et al., 2004). After checking for the absence of toxin on the bottom, extraction was carried out on the supernatant, according to the following sequences executed by the automat on SPE cartridge (C18, $500 \mathrm{mg}, 3 \mathrm{~mL})$ :

1) drying under nitrogen atmosphere and compression of silica for $4 \mathrm{~min}$,

2) conditioning of cartridge with $20 \mathrm{~mL}$ pure methanol followed by $20 \mathrm{~mL}$ water at $8 \mathrm{~mL} \mathrm{~min}{ }^{-1}$,

3) deposit of $5 \mathrm{~mL}$ supernatant at $2.50 \mathrm{~mL} \mathrm{~min}^{-1}$,

4) wash with $5 \mathrm{~mL}$ water at $3 \mathrm{~mL} \mathrm{~min}^{-1}$,

5) elution of toxins with $5 \mathrm{~mL}$ pure methanol at $3 \mathrm{~mL} \mathrm{~min}^{-1}$ and drying with $6 \mathrm{~mL}$ pulsed air. 
The $5 \mathrm{~mL}$ methanol fraction was recovered, evaporated and diluted in $100 \mu \mathrm{L}$ pure methanol. A $5 \mu L$ fraction of the final extract was injected into the HPLC/MS. The conditions used in the above protocol (sample dilution, conditioning, wash, analyte elution over cartridge, etc.) were initially designed for Prorocentrum lima cultures, and selected for criteria of yield efficiency, reproducibility and signal intensity.

Toxin detection and quantification were carried out with HPLC coupled with ion-trap mass spectrometry (Finnigan-LCQ ion trap), under the following conditions: Column and precolumn Kromasil C18 (250 mm x $2.0 \mathrm{~mm}$ I.D. $5 \mu \mathrm{m})$; temperature: $40^{\circ} \mathrm{C}$; Isocratic mobile phase: acetonitrile/water $+0.1 \%$ TFA, $(75: 25, \mathrm{v} / \mathrm{v})$; flow: $0.2 \mathrm{~mL} \mathrm{~min}^{-1}$. Data acquisition was conducted in positive mode, with alternating full MS and full MS2, providing both for universal (full) detection and for highly specific and selective detection (full MS2) in one single injection. The analysis quantifies the daughter ions.

The accuracy and reliability of this automated extraction procedure coupled with LC/MS detection were validated against two reference systems (Algrandi et al., 1992, AFNOR, 1998). According to these standards, the range of linearity was defined as 0.05 to $11.5 \mathrm{ng}$ OA or DTX1 $(n=3, p=9)$. The precision of the method as adapted to solid phases and optimized for extraction parameters was checked against a certified reference specimen of digestive gland contaminated with $11.003 \mu \mathrm{g}$. $\mathrm{OA} \mathrm{g}^{-1}$ (Quilliam, 1995). Validation tests revealed that the method was capable of detecting $63 \mathrm{pg}$ and of measuring $186 \mathrm{pg}$ OA-equivalent, with a $1 \%$ error risk and an experimental standard deviation of 66 pg (Mondeguer et al., 2004).

\section{Results}

Table 1 summarizes the characteristics of the sampling points and the results obtained. In spite of the patchiness of $D$. acuminata populations, the samples generally contained significant amounts of toxic cells: four samples only had densities below 100 cells $\mathrm{L}^{-1}$. The hypothesis assuming the Dinophysis genus to be the okadaic acid source relies on the fact that no toxins are detected - or as traces only - in samples with very low Dinophysis spp. density, and that on other occasions and in spite of the presence of Dinophysis, samples were found to be toxin-free (data not shown). Table 1 presents okadaic acid contents alone since no substituted forms (DTX1 or 2) were detected in the concentrates. 


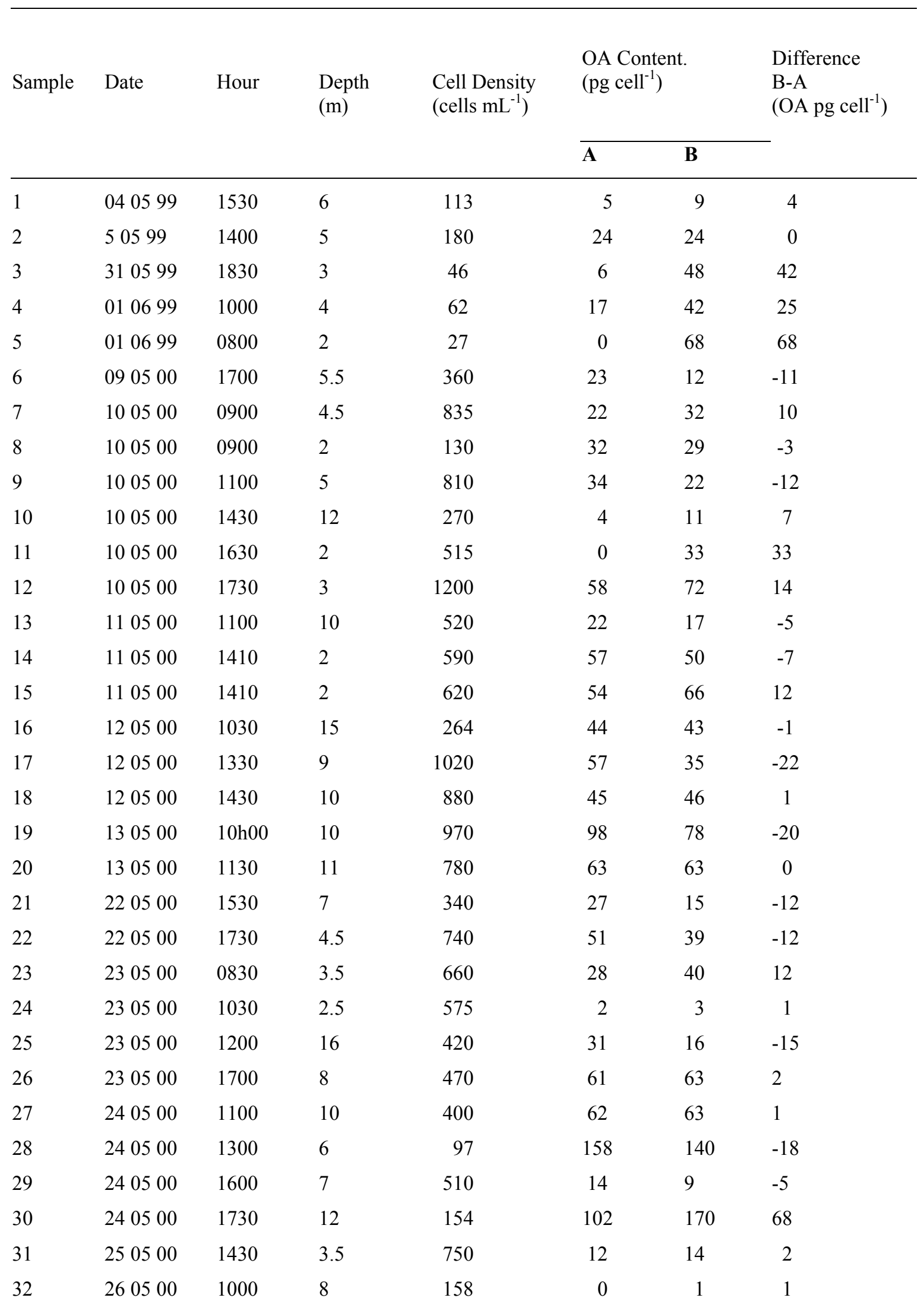

Table 1. Characteristics and okadaic acid (OA) content of phytoplankton samples after heated (A) and unheated (B) treatments. Heated treatment gives free okadaic acid and unheated treatment measures free okadaic acid + sulfated esters. 
The fractions subjected to slow thawing without prior heating revealed highly variable okadaic acid contents (Table 1): i.e. values ranging from a few pg up to $160 \mathrm{pg} \mathrm{cell}^{-1}$. The okadaic acid content variability of heated fractions was found to be roughly similar to unheated fractions (Figure 1).

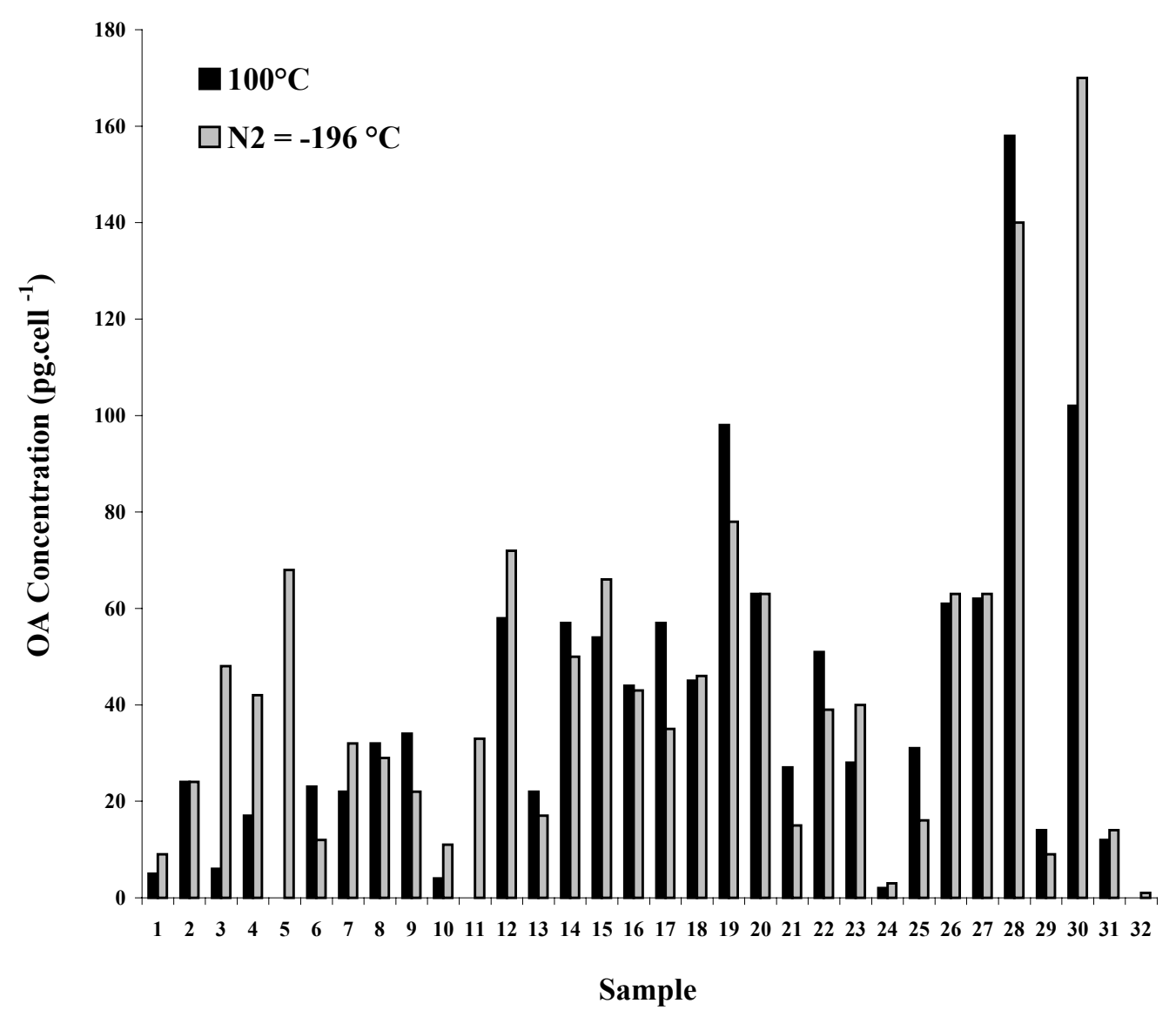

Figure 1. Influence of two different treatments on okadaic acid content of D. acuminata concentrates divided in two sub-samples: heated (black) and unheated (grey) fractions.

According to the initial tested assumption, the heated fraction should contain esters, and therefore a lower content in free okadaic acid.

Yet, not only was their okadaic acid content not systematically lower, but it was sometimes much higher, as expressed by differences between the values of unheated and heated subsamples (B-A), occurring in virtually equal numbers of cases (Figure 2): i.e. either positive, or negative (some were non-significant). 


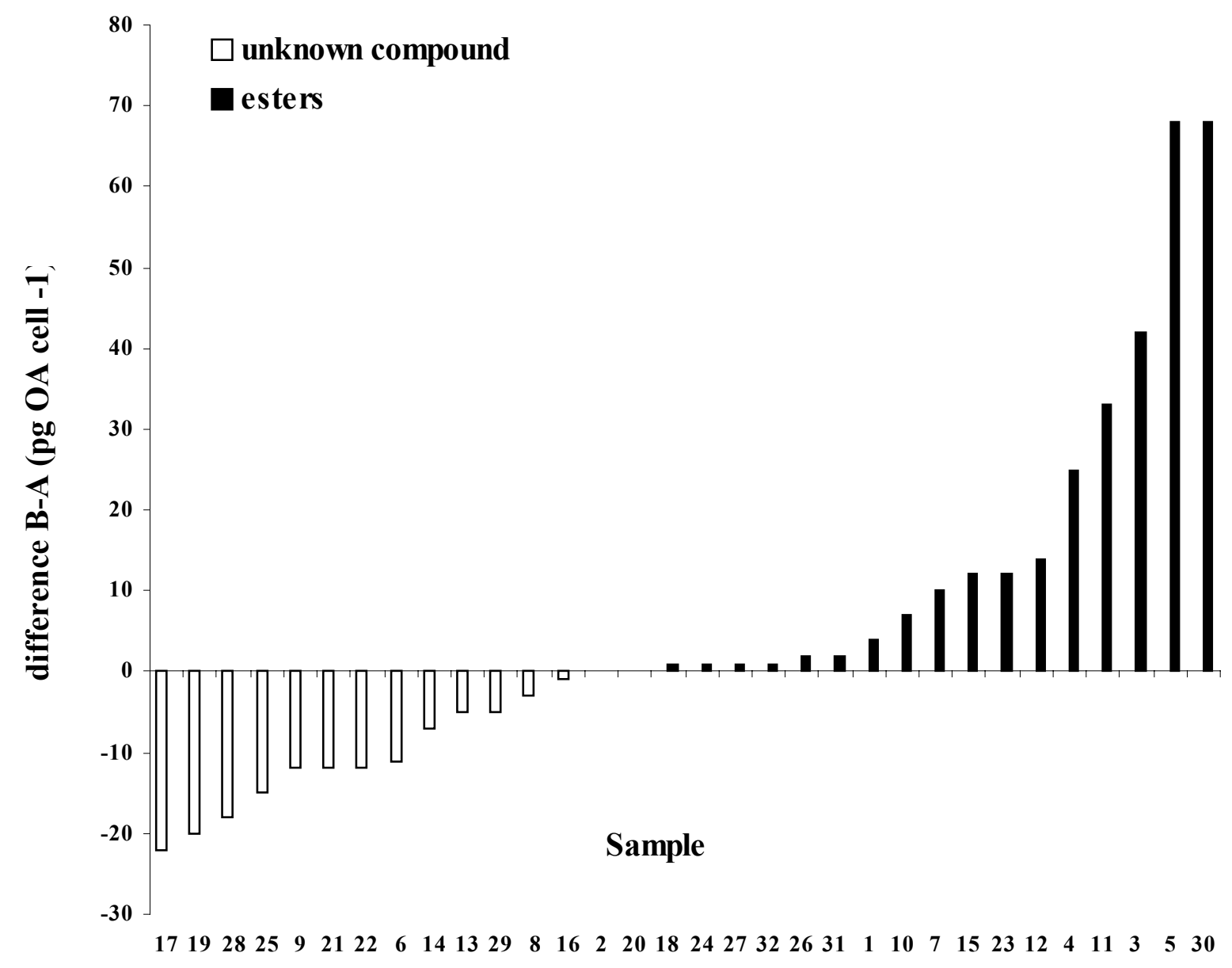

Figure 2. Classification of differences in okadaic acid content between the unheated and heated fractions and inversely: A-B: OA release from unknown compounds $(\square)$; B-A: presence of esters $(\boldsymbol{\square})$.

No relation was found with the time or depth of sampling, as illustrated by results from two consecutive sampling days. As an example, on 23 and 24 June 2000, four samples were collected within a few hours: the minimum and maximum values were $3-63 \mathrm{pg} \mathrm{cell}^{-1}$ and 9$170 \mathrm{pg} \mathrm{cell}^{-1}$, respectively for unheated and heated procedures.

\section{Discussion}

The toxicity of $D$. acuminata in this series of samples shows significant variations over a period of a few days and at a single site, while previously published values reported on samples collected over longer time and space intervals. These results would thus reflect the mean toxicity of a heterogeneous cell population at a given moment. Consequently, when attempting to relate cell density and shellfish toxicity, care should be taken to estimate intrapopulation 
specific toxicity. The okadaic acid content measured in unheated fractions are relatively higher than those previously reported, though not exceeding a few tens of pg per cell (Andersen et al., 1996), a result that could be explained by the systematic use of the slow thawing procedure in this study, which promotes the hydrolysis of esterified forms into free okadaic acid.

The presence of esters is confirmed in one-third of the sample. Their level varies from 0 to $100 \%$ (virtually no or little free OA in the heated fraction), as described by other authors. Using the same indirect detection procedure, Moroño et al. (2003) also found variable ester concentrations, but none with values exceeding 11.2 pg cell $^{1}$. In 2004, Vale showed that it was possible with this technique to recover nearly $90 \%$ of the esters contained in a Dinophysis concentrate. Finally, Suzuki et al. (2004) showed the presence of several okadaic acid derivatives in D. acuta, the most predominant being OA-D8, previously identified by Quilliam (1996).

An examination of differences in toxicity content between unheated and heated fractions however suggests the presence of (an)other form(s) that would be converted into okadaic acid under the action of heat, yet would remain stable under thawing, and could in certain cases be present in amounts greater than esters. This observation refers to the findings of Sato et al. (1996), who reported very high concentrations (230 pg equiv OA cell ${ }^{-1}$ ) measured with ELISA tests in isolated D. acuminata cells, while a chemical analysis of the same extract yielded a much lower value of $20 \mathrm{pg}$ OA+DTX1 cell ${ }^{-1}$. These authors further mention a compound different from water-soluble esters (DTX4-like), considered likely to crosslink with anti-OA antibodies and to re-form okadaic acid.

Neither dinophysistoxin-1 nor 2 were detected in this series of samples, an absence previously reported in D.acuminata concentrates from the Bay of Seine along the English Channel coast (Marcaillou Le Baut et al., 2001). These results are in accordance with most other published reports (Fernandez et al., 2000) suggesting that D acuminata should be classified among okadaic acid producers. However, some caution is needed, since Sato et al (1996) detected dinophysistoxin-1 in this species at $65 \mathrm{pg} \mathrm{cell}^{-1}$ level.

In conclusion, the analyses of this series reveal that the toxin profile of $D$. acuminata may be more complex than considered previously, and confirms its high variability. Consequently, specific toxicity expressed as a given amount of DTXs (OA and/or DTX1-2) per cell is a highly inadequate measure, particularly for any definition of a shellfish contamination model. 


\section{Acknowledgements}

This work was supported with funds from "Syndicat Mixte pour le Développement de l'Aquaculture en Pays de Loire"(SMIDAP) and the Programme National d'Océanographie Côtière (PNEC).

\section{References}

AFNOR (1998 NF V 03-110) Procédure de validation intralaboratoire d'une méthode alternative par rapport à une méthode de référence. $1^{\mathrm{er}}$ tirage 98-12-F.

Algranti P, Guilloteau M, Histe M, Lallier M, N'Guyen-Huu JJ, Russoto R (1992) Guide de validation analytique, rapport d'une commission SFSTP-Méthodologie et exemple d'application. STP PHARMA Pratiques 2: 205-226.

Andersen P, Hald B, Emsholm H (1996) Toxicity of Dinophysis acuminata in Danish coastal waters. In Yasumoto T, Oshima Y, Fukuyo Y (eds), Harmful and Toxic Algal Blooms, IOC of UNESCO, pp 281-283.

Bialojan C, Takai A (1988) Inhibitory effect of a marine sponge toxin, okadaic acid, on protein phosphatases. Biochem. J. 256: 283-290.

Fernandez ML, Reguera B, Ramilo I, Martinez A (2000) Toxin content of Dinophysis acuminata, D. acuta and D. caudata from the Galician Rias Bajas. In Hallegreaff GM, Blackburn SI, Bolch CJ, Lewis RJ (eds), Harmful Algal Blooms 2000. IOC of UNESCO, pp 360-363.

Gentien P., Lunven M., Lehaitre M., Duvent J.L. (1995). In situ depth profiling of particles sizes. Deep-Sea Res. 42: 1297-1312.

Hoshiai G, Suzuki T, Onodera T, Yamasaki M, Taguchi S (1997) A case of non toxic mussels under the presence of high concentrations of toxic dinoflagellate Dinophysis acuminata that occured in Kesennuma Bay, Northern Japan. Fisheries Science 63: 317-318.

Hu T, Curtis JM, Walter JA, Wright JLC (1995a) Identification of DTX-4, a new water-soluble phosphatase inhibitor from the toxic dinoflagellate Prorocentrum lima. J. Chem. Soc., Chem. Commun.: 597-599.

Hu T, Curtis J M, Walter J A, McLachlan J L, Wright JLC (1995b) Two new water-soluble DSP toxin derivatives from the Dinoflagellate Prorocentrum maculosum: possible storage and excretion products. Tetrahedron Letters 36 (51): 9273-9276.

Jackson D, Silke J (1995) Dinophysis spp and the occurrence of Diarrhetic Shellfish Poisons in Ireland. In: Lassus P, Arzul G, Erard E, Gentien P, Marcaillou C (eds), Harmful Marine Algal Blooms. Lavoisier Intercept Ltd, pp 789-794. 
Lee JS, Igarashi T, Fraga S, Dahl E, Hovgaard P, Yasumoto T (1989) Determination of diarrhetic shellfish toxins in various dinoflagellate species. J. appl. Phycol. 1: 147-152.

Marcaillou Le Baut C, Gentien P, Lunven M, Le Grand J, Mondeguer F, Daniélou MM, Crassous MP, Youénou A (2001) Dinophysis acuminata distribution and specific toxin content in relation to mussel contamination. In Hallegreaff GM, Blackburn SI, Bolch CJ, Lewis RJ (eds), Harmful Algal Blooms 2000. IOC of UNESCO, pp 356-359.

Marr JC, Jackson AE, McLachlan JL (1992) Occurrence of Prorocentrum lima, a DSP toxinproducing species from the Atlantic coast of Canada. J. appl. Phycol. 4: 17-24.

Mondeguer F, Genin E, Mestre G, Nsengiyumva C (2004) Validation of an automated procedure of solid phase extraction of mussel digestive glands for identification and quantification of dinophysistoxins in LC/ESI/MS2 by quadrupole ion trap. (Submitted to the 5th International Conference on Molluscan Shellfish Safety, Galway, Ireland, June 2004).

Moroño A, Arévalo F, Fernández ML, Maneiro J, Pazos Y, Salgado C, Blanco J (2003.) Accumulation and transformation of DSP toxins in mussels Mytilus galloprovencialis during a toxic episode caused by Dinophysis acuminata. Aquatic Toxicology 62: 269-280.

Quilliam MA (1995) Analysis of diarrhetic shellfish poisoning toxins in shellfish tissue by liquid chromatography with fluorometric and mass spectrometric detection. Journal of AOAC International 78: 555-569.

Quilliam MA, Hardstaff WR, Ishida N, MCLachlan JL, Reeves AR, Ross NW, Windust AJ (1996) Production of diarrhetic shellfish poisoning (DSP) toxins by Prorocentrum lima in culture and development of analytical methods. In Yasumoto T, Oshima Y and Fukuyo Y (eds), Harmful and Toxic Algal Blooms, IOC of UNESCO, pp 289-292.

Sato S, Koike K, Kodama M (1996) Seasonal variation of okadaic acid and dinophysistoxin-1 in Dinophysis spp in association with the toxicity of scallop. In Yasumoto T, Oshima Y and Fukuyo Y (eds), Harmful and Toxic Algal Blooms, IOC of UNESCO, pp 285-288.

Suzuki T, Mitsuya T, Imai M, Yamasaki M (1997) DSP toxin contents in Dinophysis fortii and scallops collected at Mutsu bay, Japan. J. appl. Phyco. 8: 509-515.

Suzuki T, Beuzenberg V, Mackenzie L, Quilliam M (2004). Discovery of okadaic acid esters in the toxic dinoflagellate Dinophysis acuta from New Zealand using liquid chromatography/ tandem mass spectrometry. Rapid Comm.Mass Spectrom. 18: 1131-1138.

Utermöhl H (1958) Zur vendhommung der quantitativen phytoplankton. Methodik. Int. Ver. Theoret. Argueur. Limnol. 9: 1-38. 
Vale P ( 2004) Differential dynamics of dinophysistoxins and pectenotoxins between blue mussel and common cockle : a phenomenon originating from the complex toxin profile of Dinophysis acuta. Toxicon 44 (2): 123-134. 